\title{
PERANCANGAN SISTEM INFORMASI DISTRIBUSI AIR BERSIH DENGAN PENDEKATAN PROTOTYPE DEVELOPMENT LIFE CYCLE
}

\author{
Aji Setiawan ${ }^{1}$, Adam Arif Budiman ${ }^{2}$, Rimba Sianturi $^{3}$, Andriansyah Zakaria $^{4}$ \\ ${ }^{1,2,3}$ Program Studi Teknik Informatika, Universitas Darma Persada \\ ${ }^{4}$ Program Studi Teknik Informatika, Politeknik Negeri Cilacap \\ aji_setiawan@ft.unsada.ac.id ${ }^{1}$, adam_arif_budiman@ft.unsada.ac.id ${ }^{2}$, rimbasianturi17@gmail.com ${ }^{3}$, \\ andrian@ politeknikcilacap.ac.id ${ }^{4}$
}

\begin{tabular}{|c|c|}
\hline & Abstrak \\
\hline $\begin{array}{l}\text { Kata Kunci: } \\
\text { Arduino Uno; } \\
\text { Solenoid; } \\
\text { Water Flow Sensor, } \\
\text { System Distribusi Air. }\end{array}$ & $\begin{array}{l}\text { Pendistribusian air pada Rumah Susun Klender Jakarta Timur hingga saat ini masih belum } \\
\text { merata, sehingga beberapa penghuni rusun mengalami kekurangan air. Mengingat air } \\
\text { merupakan kebutuhan utama dalam kehidupan sehari-hari. Untuk mengatasi permasalahan yang } \\
\text { terjadi maka dibuatlah alat yang dapat mengukur debit air dan mengatur pendistribusian air } \\
\text { dengan menggunakan Arduino Uno. Alat ini menggunakan piranti berupa katup solenoid dan } \\
\text { water flow sensor yang disambukan ke Arduino Uno. waterflow sensor akan menghitung } \\
\text { jumlah air yang telah dipakai dan setelah mencapai kapasitas maksimal katup solenoid akan } \\
\text { menghentikan distribusi air sesuai dengan kapasitas maksimal setiap kepala keluarga (KK). } \\
\text { Untuk menerapkan alat tersebut kedalam sistem, penulis menggunakan bahasa pemrograman C } \\
\text { dan untuk halaman website menggunakan PHP. Pemakaian air akan dipantau setiap satu jam } \\
\text { dan system akan mengirimkan data ke database untuk ditampilkan kehalaman monitoring yang } \\
\text { terdapat pada website dalam bentuk grafik. }\end{array}$ \\
\hline
\end{tabular}

\begin{tabular}{ll}
\hline & Abstract \\
\hline $\begin{array}{l}\text { Keywords: } \\
\text { Arduino Uno; }\end{array}$ & $\begin{array}{l}\text { The water in the Klender Flats in East Jakarta is still not evenly distributed; therefore some of } \\
\text { the residents are increasingly lacking in water. Considering water is the prime necessity in } \\
\text { everyday life, a tool that can measure water flow and regulate the distribution of water using } \\
\text { Water Flow Sensor, } \\
\text { Water Distribution }\end{array}$ \\
$\begin{array}{l}\text { Arduino Uno is made to overcome the problems that occur. This tool uses a device consisting of } \\
\text { a solenoid valve and a water flow sensor that is sent to Arduino Uno. Water flow sensor will } \\
\text { calculate the amount of water that has been used and after reaching the maximum capacity the } \\
\text { solenoid valve will flow water distribution in accordance with the maximum capacity of each } \\
\text { family (KK). To implement the tool into the system, the writer uses C programming language } \\
\text { and for the website, the writer use PHP. The use of water will be monitored every one hour and } \\
\text { the system will send data to the database for retrieving necessary monitoring data on the website } \\
\text { in graphical form. }\end{array}$
\end{tabular}

\footnotetext{
๑lamat korespondensi:

E-mail: aji_setiawan@ft.unsada.ac.id

ISSN : 2087-1627
} 


\section{Pendahuluan}

Kebutuhan air untuk keperluan sehari - hari sangat penting dan harus tercukupi. Pada rumah susun klender blok 48 kebutuhan air sampai saat ini tidak terbagi secara merata pada setiap rumah dikarenakan mesin untuk memompa air tidak bekerja selama 24 jam melainkan 15 jam dalam sehari dan kemampuan mesin pompa yang hanya mampu menghisab air 5-7 liter / menit yang menyebabkan kebutuhan air menjadi terbatas dan kesadaran dari sesama penghuni rumah susun yang masih kurang akan kebutuhan air sehingga sebagian dari penghuni rumah susun tidak mendapatkan kebutuhan air yang tercukupi..

Beberapa solusi sudah di coba agar kebutuhan air pada rumah susun dapat terpenuhi secara merata yaitu dengan melakukan pengoptimalan kinerja pompa air menjadi 24 jam dan beralih menggunakan PAM (Perusahaan Air Minum), tetapi tidak semua penghuni rumah susun setuju karena keterbatasan ekonomi, sehingga sampai pada saat ini seluruh penghuni rumah susun blok 48 hanya mamanfaatkan sumur dan kinerja mesin untuk memenuhi kebutuhan air setiap harinya.

Banyaknya air yang akan di distribusikan ke penghuni rusun mengacu pada Peraturan Menteri Pekerjaan Umum Nomor : 14 /PRT/M/2010 tentang standar pelayanan minimal bidang pekerjaan umum dan penataan ruang, Pasal 5 mengenai perihal air minum menjelaskan bahwa kebutuhan minimal air per orang per hari adalah 60 liter.

Berdasarkan permasalahan yang pemecahan solusinya dengan merancang dan membuat suatu sistem pendistribusian air dengan konsep Internet of Things (IoT). Sistem pendistribusian kebutuhan air ini nantinya akan menggunakan perangkat solenoid valve yang berfungsi sebagai katup untuk membuka dan menutup aliran air yang mengalir pada pipa dan water flow sensor yang berfungsi untuk menghitung banyaknya air mengalir yang dihubungkan ke arduino. Pengaturan jatah distribusi air dilakukan melalui aplikasi web sedangkan untuk penyimpanan data menggunakan MySQL.

\section{Tinjauan Studi}

\subsection{Internet of Things}

Internet of Things (IoT) adalah pendekatan baru yang menghubungkan hal-hal / objek dan dengan demikian mentransmisikan informasi ke pusat fisik di mana informasi ini dapat ditafsirkan. IoT telah dianggap sebagai evolusi berikutnya dari pemasaran internet untuk memungkinkan akses tanpa batas ke orang dan perangkat. Perangkat ini, seringkali perangkat yang merupakan peralatan rumah tangga, perangkat kesehatan, kendaraan, bangunan, dan hampir semua jaringan dan dilengkapi dengan sensor, aktuator, dan komputer tertanam. [1]

\subsection{Mikrokontroler Arduino}

Hardware Arduino sama dengan mikrokontroler pada umumnya hanya pada arduino ditambahkan penamaan pin agar mudah diingat. Software Arduino merupakan software open source sehingga dapat di download secara gratis. Software ini digunakan untuk membuat dan memasukkan program ke dalam Arduino. Pemrograman Arduino tidak sebanyak tahapan mikrokontroler konvensional karena Arduino sudah didesain mudah untuk dipelajari, sehingga para pemula dapat mulai belajar mikrokontroler dengan Arduino. Beberapa penelitian terkait faktor keamanan juga telah dilakukan salah satunya mengenai analisis keamanan Arduino Yun, hasil penelitian menunjukkan bahwa Arduino Yun rentan terhadap sejumlah serangan [2].

\section{Metode Penelitian}

Metode pengembangan sistem yang digunakan dalam menyelesaikan tugas akhir ini adalah menggunakan SDLC (System Development Life Cycle) model Prototype [3]. Berikut tahapannya:

a) Pengumpulan Kebutuhan

Pelanggan dan pengembang bersama - sama mendefinisikan format dan kebutuhan keseluruhan perangkat, mengidentifikasikan semua kebutuhan dan garis besar sistem yang akan dibuat.

b) Membangun prototyping

Membangun prototyping dengan membuat perancangan sementara yang berpusat pada penyajian kepada pelanggan misalnya dengan membuat input dan contoh outputnya.

c) Evaluasi prototyping

Evaluasi ini dilakukan oleh pelanggan apakah prototyping yang sudah dibangun sudah sesuai dengan keinginan. Jika sudah sesuai maka langkah keempat akan diambil. Jika tidak, maka prototyping diperbaiki dengan mengulang langkah 1,2 dan 3 .

d) Mengkodekan sistem

Dalam tahap ini prototyping yang sudah disepakati diterjemahkan kedalam bahasa pemrograman yang sesuai.

e) Menguji sistem

Setelah sistem sudah menjadi suatu perangkat yang siap pakai, harus dites dahulu sebelum digunakan.

\section{f) Evaluasi sistem}

Pengguna mengevaluasi siapakah sistem yang sudah jadi sudah sesuai dengan yang diharapkan. Jika sudah, maka langkah ketujuh dilakukan, jika belum maka mengulangi langkah 1 dan 2 . Perangkat lunak yang telah diuji dan diterima pelanggan siap untuk digunakan.

\section{Hasil dan Pembahasan}

Sebagai bagian dari perencanaan, dilakukan perencanaan dengan menggunakan UML [4] seperti 
use case [5], dan activity diagram[6]. Untuk use case dapat digambarkan sebagai berikut :

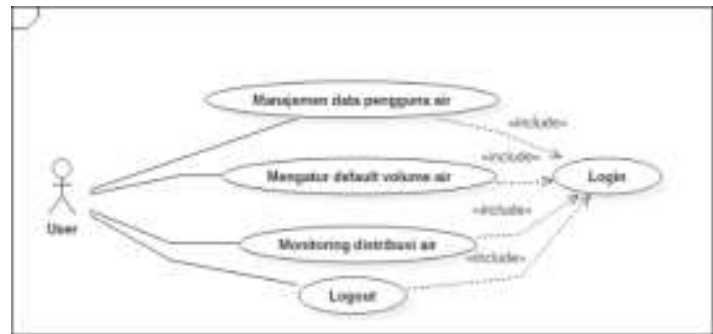

Gambar 1. Use case diagram manajemen dan monitoring air

Use case berikut menggambarkan, apa saja yang dapat dilakukan oleh arduino sebagai sistem yang bertugas mengambil data dari sensor yang kemudian akan dikirimkan ke database.

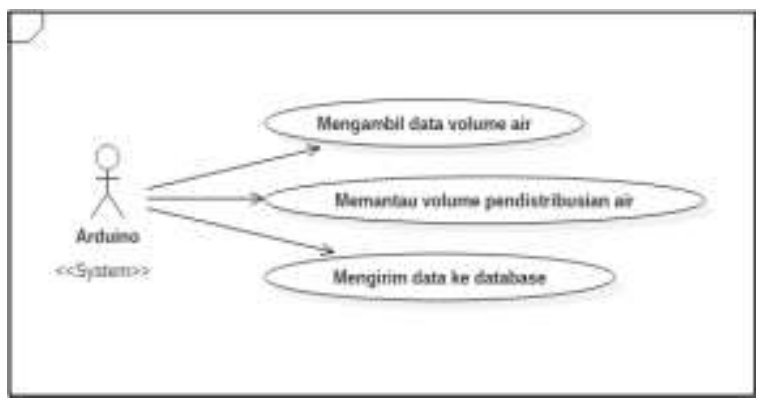

Gambar 2. Use case diagram sistem monitoring

\subsection{Rancangan Arsitektur}

Pada bagian ini akan dijelaskan mengenai perancangan arsitektur baik itu pada sistem dan aplikasi website. Pada arsitektur sistem monitoring air seperti pada Gambar 3, terdapat water flow sensor untuk menghitung jumlah debit air, solenoid valve sebagai alat untuk menghentikan pendistribusi air, router sebagai penghubung PC client dengan arduino dan arduino uno sebagai perangkat untuk mengontrol sensor dan solenoid seperti pada Gambar 4.

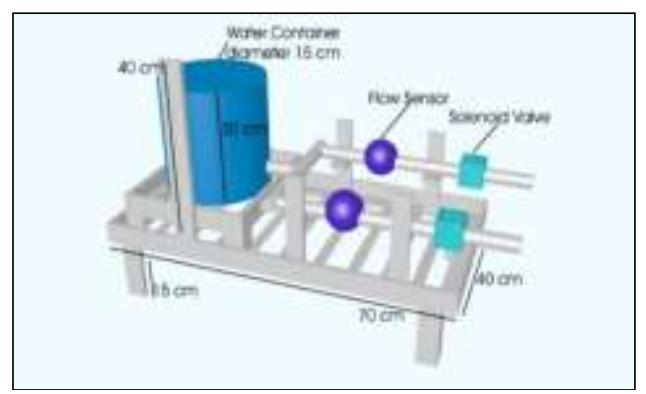

Gambar 3. Rancangan sistem distribusi air

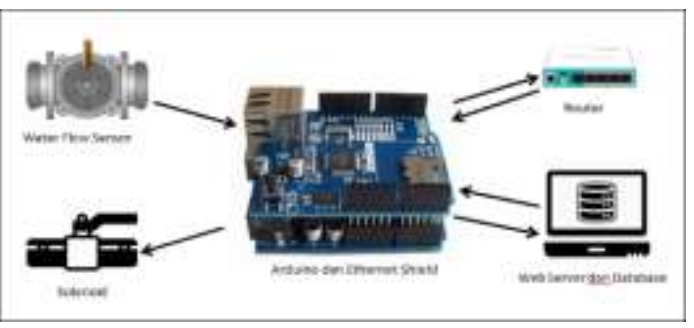

Gambar 4. Arsitektur sistem monitoring air

Tampilan web memuat data monitoring saat ini, dengan range waktu yang sudah ditentukan serta halaman dengan konten yang akan digunakan oleh admin, diperlihatkan Gambar 5 dan Gambar 6.

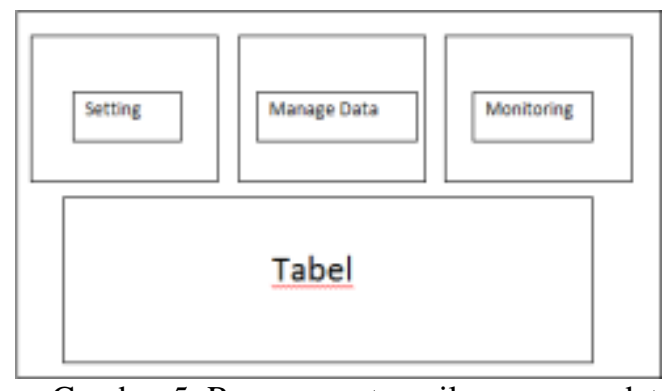

Gambar 5. Rancangan tampilan manage data

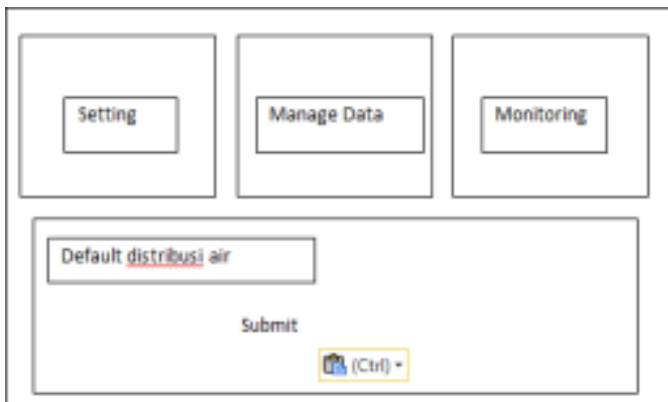

Gambar 6. Rancangan tampilan setting default kuota air

\subsection{Perangkat Mikrokontroller}

Ethernet shield akan disambungkan ke arduino uno dengan pin, water flow sensor,solenoid valve, akan disambungkan ke arduino menggunakan kabel jumper, ethernet shield yang sudah tersambung dengan arduino akan di hubungkan ke router menggunakan kabel rj45 agar data dapat diproses.

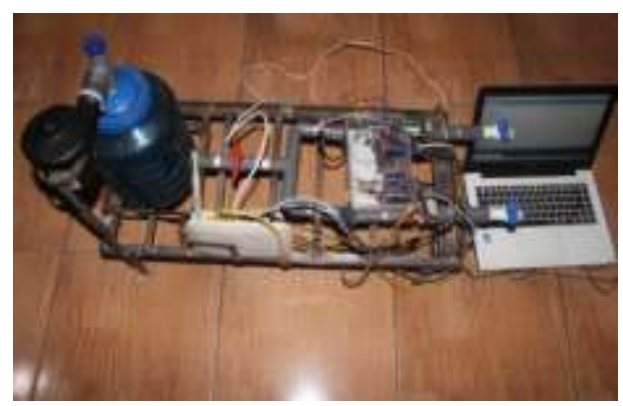

Gambar 7. Sistem monitoring air yang telah dirangkai tampak samping 


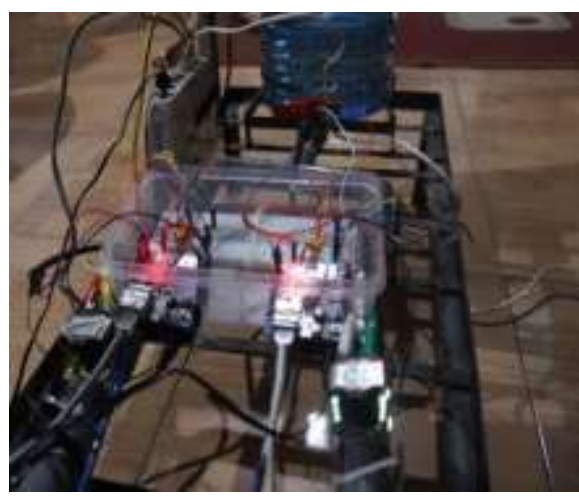

Gambar 8. Sistem monitoring air yang telah dirangkai

\subsection{Implementasi Aplikasi Web}

Pada bagian ini akan dijelaskan mengenai spesifikasi perangkat yang digunakan dalam mengakses web dan hasil uji coba sewaktu mengkases halaman web menggunakan perangkat yang sudah ditentukan.

Pada Gambar 10 adalah tampilan halaman manage data, pada menu ini admin dapat melihat, menambahkan, menghapus serta memperbarui data - data pengguna air yang akan didistribusikan.

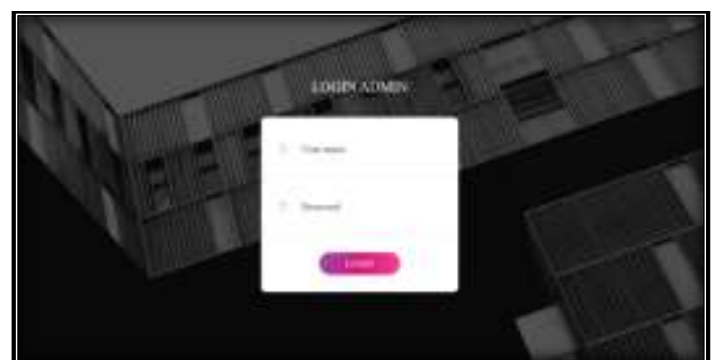

Gambar 9. Tampilan halaman login

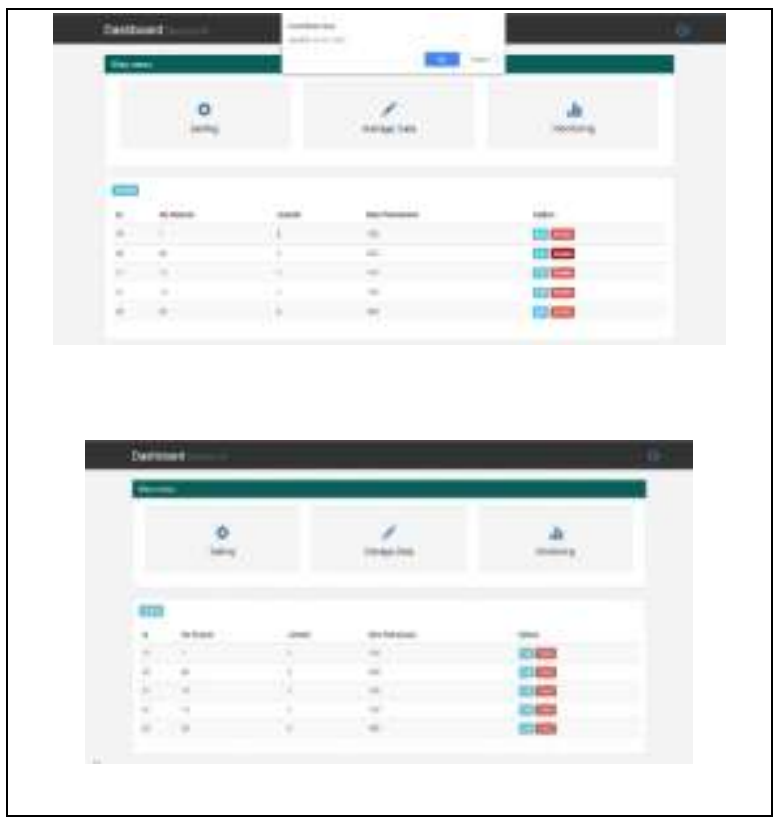

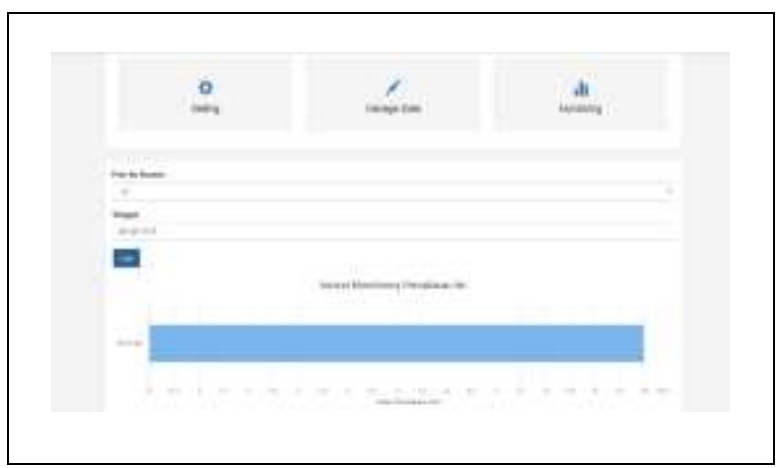

Gambar 10. Gambar dibawah ini adalah tampilan halaman monitoring air

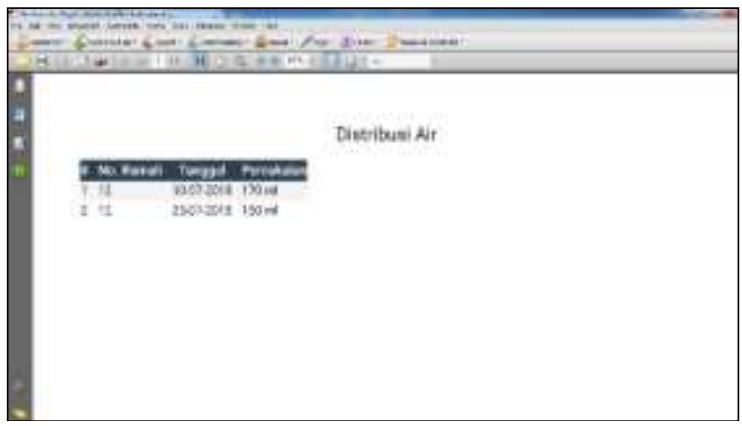

Gambar 11. Laporan Distribusi Air

\subsection{Hasil uji coba sistem}

Hasil uji coba dari sistem dan aplikasi yang telah dirancang sebelumnya, baik itu dari segi tampilan maupun segi program telah berjalan baik walaupun belum sempurna. Arduino sudah dapat menjalankan perintah untuk melakukan monitoring air dan mengirimkan data ke database. solenoid valve dan water flow sensor yang disambungkan ke arduino juga berfungsi dengan baik. Secara keseluruhan sistem berjalan dengan baik. Berikut hasil dari uji coba sistem yang disajikan dalam bentuk tabel :

Tabel 1. Hasil Uji Coba

\begin{tabular}{|c|c|c|c|}
\hline Penampungan & $\begin{array}{c}\text { Maksimal } \\
\text { Pemakaian }\end{array}$ & Output & Selisih \\
\hline 5 Liter & $400 \mathrm{ml}$ & $420 \mathrm{ml}$ & $+20 \mathrm{ml}$ \\
\hline 4,5 Liter & $400 \mathrm{ml}$ & $408 \mathrm{ml}$ & $+8 \mathrm{ml}$ \\
\hline 4 Liter & $400 \mathrm{ml}$ & $397 \mathrm{ml}$ & $-3 \mathrm{ml}$ \\
\hline 3,5 liter & $400 \mathrm{ml}$ & $390 \mathrm{ml}$ & $-10 \mathrm{ml}$ \\
\hline 3 Liter & $400 \mathrm{ml}$ & $395 \mathrm{ml}$ & $-5 \mathrm{ml}$ \\
\hline 2,5 Liter & $400 \mathrm{ml}$ & $382 \mathrm{ml}$ & $-18 \mathrm{ml}$ \\
\hline 2 Liter & $400 \mathrm{ml}$ & $387 \mathrm{ml}$ & $-13 \mathrm{ml}$ \\
\hline 1,5 Liter & $400 \mathrm{ml}$ & $394 \mathrm{ml}$ & $-6 \mathrm{ml}$ \\
\hline 1 Liter & $400 \mathrm{ml}$ & $378 \mathrm{ml}$ & $-22 \mathrm{ml}$ \\
\hline $500 \mathrm{ml}$ & $400 \mathrm{ml}$ & $386 \mathrm{ml}$ & $-14 \mathrm{ml}$ \\
\hline $400 \mathrm{ml}$ & $400 \mathrm{ml}$ & $392 \mathrm{ml}$ & $-8 \mathrm{ml}$ \\
\hline $300 \mathrm{ml}$ & $300 \mathrm{ml}$ & $274 \mathrm{ml}$ & $-26 \mathrm{ml}$ \\
\hline
\end{tabular}

Berikut masalah-masalah yang ditemukan selama penelitian dan cara mengatasinya : 
Tabel 2. Masalah hasil pengujian

\begin{tabular}{|c|c|c|}
\hline No & Masalah & Solusi \\
\hline 1 & $\begin{array}{l}\text { Katup } \\
\text { solenoid } \\
\text { valve tidak } \\
\text { terbuka } \\
\text { Sepenuhnya }\end{array}$ & $\begin{array}{l}\text { Gunakan tambahan } \\
\text { Adaptor } 12 \mathrm{~V} \text { dan pin Vin } \\
\text { untuk mendapatkan catu } \\
\text { daya yang } \\
\text { cukup,dikarenakan } \\
\text { solenoid valve } \\
\text { membutuhkan daya } \\
\text { dengan range } 9-12 \mathrm{~V}\end{array}$ \\
\hline 2 & $\begin{array}{l}\text { Water flow } \\
\text { sensor tidak } \\
\text { menghitung } \\
\text { debit air }\end{array}$ & $\begin{array}{l}\text { Periksa kabel jumper yang } \\
\text { menghubungkan water } \\
\text { flow sensor dengan } \\
\text { arduino }\end{array}$ \\
\hline 3 & $\begin{array}{l}\text { Water flow } \\
\text { sensor } \\
\text { menghitung } \\
\text { debit air } \\
\text { tetapi tidak } \\
\text { tersimpan } \\
\text { pada } \\
\text { database }\end{array}$ & $\begin{array}{l}\text { Buka serial monitor yang } \\
\text { terdapat pada menu } \\
\text { aplikasi arduino untuk } \\
\text { melihat apakah arduino } \\
\text { sudah terkoneksi dengan } \\
\text { Lan atau tidak }\end{array}$ \\
\hline 4 & $\begin{array}{l}\text { Solenoid } \\
\text { valve cepat } \\
\text { panas }\end{array}$ & $\begin{array}{l}\text { Gunakan solenoid valve } \\
\text { dengan kualitas yang } \\
\text { lebih baik,untuk } \\
\text { pemakaian jangka panjang } \\
\text { sebaiknya menggunakan } \\
\text { solenoid yang berbahan } \\
\text { besi untuk menghindari } \\
\text { kerusakan pada solenoid }\end{array}$ \\
\hline 5 & $\begin{array}{l}\text { Banyaknya } \\
\text { air yang } \\
\text { keluar tidak } \\
\text { sesuai }\end{array}$ & $\begin{array}{l}\text { Suhu dapat } \\
\text { mempengaruhi hasil dari } \\
\text { kalibrasi } \\
\text { sebelumnya,untuk } \\
\text { penyimpanan alat-alat } \\
\text { sebaiknya tidak dipindah } \\
\text { - pindah }\end{array}$ \\
\hline
\end{tabular}

\section{Kesimpulan}

Sistem monitoring air ini dirancang untuk mempermudah proses distribusi air yang belum merata pada Rumah Susun Klender Jakarta Timur. Water flow sensor yang disambungkan pada Arduino akan secara otomatis menghitung debit air yang didistribusikan ke penghuni rusun, saat pemakaian air sudah maksimal maka distribusi air akan diberhentikan dengan menutup aliran air menggunakan Solenoid valve. Data penghuni rusun akan disimpan terlebih dahulu pada database, berdasarkan data yang sudah tersimpan maka akan didapatkan maksimal pemakaian dari setiap rumah, pemakaian maksimal dari setiap penghuni rusun berbeda - beda berdasarkan jumlah anggota keluarga yang menempati rumah tersebut. Untuk penambahan pengguna baru, admin terlebih dahulu memasukkan data pengguna untuk mendapatkan maksimal penggunaan air. Semua proses yang terjadi di Arduino uno menggunakan bahasa pemrograman $\mathrm{C}$ dan terhubung dengan internet sedangkan aplikasi website menggunakan bahasa pemrograman PHP dan JavaScript serta database $M Y S Q L$.

Berdasarkan hasil uji coba yang sudah dilakukan, beberapa saran untuk pengembangan sistem dan aplikasi ini selanjutnya, diantaranya adalah perubahan terhadap interface agar nantinya dapat mempermudah penggunaan sistem tersebut, pPenambahan fitur perawatan mesin dan pembayaran air pada aplikasi, membuat kontrol solenoid menggunakan tombol,menggantikan keran air konvensional, menggunakan power supply untuk penguat daya solenoid agar catu daya tercukupi, merakit magnetik solenoid tersendiri agar solenoid dapat digunakan dalam waktu yang lama, dan untuk menghemat biaya satu arduino dapat mengontrol sampai sepuluh solenoid dan water flow sensor.

\section{Daftar Pustaka:}

[1] T. Davies, "Internet of things," Journal of the Institute of Telecommunications Professionals. 2015.

[2] L. P. Prieto, M. J. Rodríguez-Triana, M. Kusmin, and M. Laanpere, "Smart school multimodal dataset and challenges," in CEUR Workshop Proceedings, 2017.

[3] M. Apoorva and D. Deepty, "A Comparative Study of Different Software Development Life Cycle Models in Different Scenarios," Int. J. Adv. Res. Comput. Sci. Manag. Stud. Res., 2013.

[4] J. Rumbaugh, "Unified Modeling Language (UML)," in Encyclopedia of Software Engineering, 2016.

[5] U. Case, "3: Use cases," A Student Guid. to Object-Oriented Dev., 2005.

[6] S. W. Ambler, "UML Activity Diagrams," in The Elements of UML ${ }^{T M} 2.0$ Style, 2011. 